\title{
Heterogeneous catalytic oxidation of phenol by in situ generated hydrogen peroxide applying novel catalytic membrane reactors
}

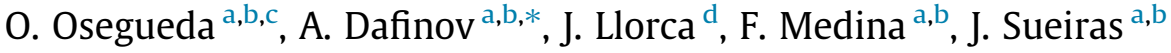 \\ ${ }^{a}$ Chemical Engineering Department, Rovira i Virgili University, Av. Països Catalans 26, Tarragona 43007, Spain \\ ${ }^{\mathrm{b}}$ EMas-Research Center on Engineering of Materials and Micro/nanoSystems, Campus Sescelades, Tarragona 43007, Spain \\ 'Central American University “José Simeón Cañas", Blvd. Los Próceres, Antiguo Cuscatlán, El Salvador \\ ${ }^{\mathrm{d}}$ Institute of Energy Technologies and Centre for Research in NanoEngineering, Universitat Politècnica de Catalunya, Diagonal 647, 08028 Barcelona, Spain
}

\section{H I G H L I G H T S}

- Selective deposition of active phase on the reaction zone.

- Formation of nanometer sized palladium particles.

- High selectivity to hydrogen peroxide in the $\mathrm{H}_{2}$ oxidation.

- Efficiently use of in situ generated hydrogen peroxide.

- Role of the hydrogen in the Pd deactivation process.

\section{A R T I C L E I N F O}

\section{Article history:}

Received 23 May 2014

Received in revised form 18 September

2014

Accepted 19 September 2014

Available online 7 October 2014

\section{Keywords:}

Hydrogen peroxide generation

Catalytic membrane reactor

Sputtered palladium nanoparticles

Phenol oxidation

Palladium nanoparticle deactivation
G R A P H I C A L A B S T R A C T

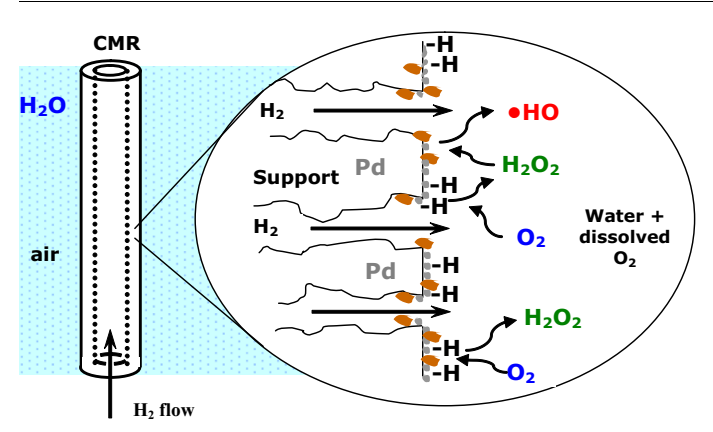

\section{A B S T R A C T}

This work presents a novel method for oxidation of organic matter in water solutions based on catalytic membrane reactors. The oxidant, hydrogen peroxide, is generated directly in the bulk of the liquid investigated. Commercial symmetric alumina hollow fibers have been used as a starting material thereafter introducing the active phases. It has been proven that two different catalysts are necessary in order to complete the overall reaction, as well as to generate hydrogen peroxide and a heterogeneous Fenton process. Palladium has been used for the hydrogen peroxide generation and a second active phase, transitional metal oxides or homogeneous $\mathrm{Fe}^{2+}$, has been used for the hydroxyl radical generation. An additional method for specific Pd loading to the reaction zone based on sputtering technique has been developed. All prepared catalytic membrane reactors (CMRs) are capable of generating hydrogen peroxide in amounts comparable to CMRs reported in the literature. The catalytic membrane reactors prepared by Pd impregnation show very high activity and stability in phenol oxidation reaching $40 \%$ of the generated $\mathrm{H}_{2} \mathrm{O}_{2}$ usage in the oxidation reaction. Despite the very high activity of the catalytic membrane reactors obtained by Pd sputtering in $\mathrm{H}_{2} \mathrm{O}_{2}$ production they suffer very fast deactivation. Specific reactivation including a calcination step has been found to be appropriate for the recovery of their activity. Additional experiments give new insights for better understanding of Pd deactivation especially when the metal particles are of nanometer sizes.

(c) 2014 Elsevier B.V. All rights reserved.

\footnotetext{
* Corresponding author at: Chemical Engineering Department, Rovira i Virgili University, Av. Països Catalans 26, Tarragona 43007, Spain. Tel.: +34 977558112; fax: +34 977559621.
}

E-mail address: anton.dafinov@urv.cat (A. Dafinov). 


\section{Introduction}

Phenol compounds are the most common pollutants present in the wastewaters from chemical, petrochemical and pharmaceutical industrial processes. Attending to stronger environmental regulation, phenol and related aromatic compounds cannot be discharged in industrial effluent due to their high toxic effect on the aquatic life and possible groundwater contamination [1-3]. Conventional wastewater treatment methods such as biological reactors are not useful against phenol contamination; the main reason resides in the low biodegradation efficiency and the negative effect on the microbial process [4]. However, advance oxidation processes (AOPs) are a group of chemical oxidation techniques. AOP are based in the generation of hydroxyl radical $\left(\mathrm{OH}^{\cdot}\right)$ with a high oxidation potential that is sufficient for oxidizing these type of compounds [2-5].

One of the most known AOP is the catalytic Fenton reaction. This chemical remediation technique uses hydrogen peroxide and ferrous ions $\left(\mathrm{Fe}^{2+}\right)$ which catalyze the generation of $\mathrm{OH}$. This technology is available commercially but possesses some drawbacks: it works under acid conditions (range of $\mathrm{pH} 2.5-3.5$ ), require from 5 to 10 time the stoichiometric amount of $\mathrm{H}_{2} \mathrm{O}_{2}$, and the catalyst recovery requires several steps that increase the operational costs [6,7]. Different approaches have been developed to turn the homogeneous Fenton reaction to heterogeneous one, known as Fenton-like processes [8,9]. Also, various emphases have been made concerning $\mathrm{H}_{2} \mathrm{O}_{2}$ dosage, $\mathrm{pH}$, temperature, type of heterogeneous catalyst (e.g., nanoparticles, different metals including noble ones supported on different types of supports etc. [10]) to increase the oxidation efficiency. Nevertheless, AOPs based on hydrogen peroxide as oxidant are applied in a few specific cases due to the cost of the $\mathrm{H}_{2} \mathrm{O}_{2}$. Several authors have observed toxic effect of the non-reacted hydrogen peroxide over the aquatic living organisms [4-6].

An attractive alternative for catalytic oxidation with hydrogen peroxide (CWHPO) are the catalytic membrane reactors (CMRs). CMRs possess considerable advantages over conventional heterogeneous catalysts, e.g. they work under a wide range of temperatures and pressures, they are $\mathrm{pH}$ resistant in the entire range, the oxidant can be efficiently dosed and uniformly delivered to the active catalyst sites. These features of the CMRs contribute to improve the contact between the contaminated water and the chemical oxidant and at the same time the catalyst deactivation can be avoided; if desired, complete mineralization of the organic pollutants can be achieved [11-16].

Furthermore, the inherent properties of the CMRs permit the direct synthesis of hydrogen peroxide starting from $\mathrm{H}_{2}$ and $\mathrm{O}_{2}$ using noble metal as an active phase [13-20]. The catalytic membrane reactors have a well defined three phase contact zone for gas-liquid reactions. The gas and liquid phases are introduced from the opposite sides of the membrane into the reaction zone. This method avoids the formation of an explosive mixture and the efficiency of the hydrogen consumption can be increased considerably. Because of the simplicity of the process it can be performed directly in the wastewaters effluents, where the in situ generated hydrogen peroxide will be directly involved in a subsequent reaction of e.g. organic matter oxidation.

The hydrogen peroxide generation starting from hydrogen and oxygen from air has been described in detail in our previous work [19]. The efficiency of hydrogen involved in the peroxide formation reaction was determined in all cases as along with the formation rate and the maximum achievable peroxide concentration. It was demonstrated that the generated hydrogen peroxide oxidized the surface of the Pd leading to its deactivation in the course of the studied reaction. Some initial experiments were carried out in which the hydrogen peroxide was generated in phenol containing solution. The generated oxidant was consumed in the subsequent oxidation reaction so no catalyst deactivation was observed. In order to complete this so called hybrid process it was necessary to incorporate a second active phase into the catalytic membrane reactor, e.g. cerium oxide, iron oxide etc. which are active for peroxide radicals formation starting from $\mathrm{H}_{2} \mathrm{O}_{2}$ [19].

The present work is a continuation of the previous one: it is focused on the application of the CMRs for direct oxidation of a model organic compound by the in-situ generated hydrogen peroxide. Different CMRs were prepared and tested in different conditions for catalytic oxidation of phenol in water solutions by the in-situ generated hydrogen peroxide. The studied reaction was followed by monitoring the efficiency of hydrogen conversion to hydrogen peroxide, the ratio of $\mathrm{H}_{2} \mathrm{O}_{2}$ to phenol oxidation, the reaction temperature, the intermediate products of oxidation, the phenol conversion, the total organic carbon (TOC) conversion as well as the chemical oxygen demand (COD) conversion. The concept presents some advantages over the traditional technologies e.g. no acidification was required, and the reactions was carried out at atmospheric pressure and low temperature up to $60^{\circ} \mathrm{C}$, and no catalysis leaching was detected.

We propose and develop a new methodology for preparation of CMRs. In this case the palladium is uniformly deposited onto the outer surface of the ceramic fibers by means of sputtering techniques. Following this new route the Pd is introduced predominantly to the reaction zone which accounts for a higher activity of these catalytic membrane reactors for the studied reactions as well as for more than 200 fold decrease of the noble metal content. Despite of the advantages of the Pd sputtered CMRs they suffer a rather fast deactivation. In order to obtain a better understanding of the causes for the observed deactivation additional studies are performed. It has been proved that it is not essentially due to the palladium surface deactivation caused by the hydrogen peroxide. Finally, we propose a tentative mechanism for the palladium deactivation as well as suggestions for overcoming this disadvantage.

\section{Experimental}

Commercial ceramic micro- and nanofiltration hollow fiber membranes purchased from Ceparation ${ }^{\mathrm{TM}}$ were used as starting material for the preparation of the catalytic membrane reactors. The membranes were symmetric and prepared of $\alpha-\mathrm{Al}_{2} \mathrm{O}_{3}$, with dimensions ID $2 \mathrm{~mm}$ and OD $3 \mathrm{~mm}$, pH resistance $1-14$, temperature up to $1000^{\circ} \mathrm{C}$ and burst pressure of 50 bar. Various nominal filtration pore sizes were used $(4,20,100,500,800$ and $1400 \mathrm{~nm})$.

\subsection{Catalytic membrane reactors prepared by impregnation method}

The procedure followed for the preparation of Pd monometallic and double active phase (palladium-metal oxide) catalytic membrane reactors was described in detail in our previously work [19].

\subsection{Catalytic membrane reactors prepared by sputtering technique}

In order to reduce the amount of palladium as well as to disperse it finely in the reaction zone a new methodology was developed.

The metal is deposited onto the ceramic membrane from a palladium target using a sputtering technique. The constructed assembly consists of a small dc motor coupled by means of gears to the support where the membrane is fixed. The membrane fiber is inserted over metal wire, one end is fixed to the rotor and the other is laid on support. The current is supplied from $2 \times 1.5 \mathrm{~V}$ batteries. The membrane angular velocity was adjusted to $90 \mathrm{rpm}$. The deposition of the palladium was done in a sputtering chamber 
(K575X sputter coater, Qourom Technologies). The spinning of the membrane had started just before the device was introduced into the sputtering chamber. During the sputtering process the base where the membrane was placed was also rotating assuring a homogeneous deposition of Pd on the outer surface of the membrane. A reference material (a glass plate) was placed in the immediate vicinity and at the same height as the membrane. It was used later to determine the thickness of the Pd layer by means of X-ray reflectometry, from which the amount of Pd deposited onto the membrane was calculated.

The sputter coater was equipped with a turbo molecular pump with a background vacuum in the low $10^{-5} \mathrm{~Pa}$. A Pd target with 99.95\% purity (Hauner metallische werkstoffe) was used. The deposition was carried out using pure argon as a working gas. The chosen conditions for the Pd deposition were $30 \mathrm{~mA}$ current for $90 \mathrm{~s}$ of exposition. The hollow fiber membranes used as supports for the Pd deposition were pretreated with a $10 \%$ nitric acid $\left(\mathrm{HNO}_{3}\right)$ solution in order to partially hydrolyze the membrane surface and then were dried at $120^{\circ} \mathrm{C}$.

The catalytic membrane reactors prepared by sputtering of the Pd are abbreviated thereafter SCMR.

\subsubsection{Preparation of CMRs with palladium active phase}

One series of membranes were prepared following the procedure described above. Once the sputtering was performed the membranes were calcined at $400{ }^{\circ} \mathrm{C}$ overnight. The activation was performed in flowing hydrogen at $350^{\circ} \mathrm{C}$ for $2 \mathrm{~h}$ followed by cooling in inert atmosphere (argon or helium) to ambient temperature.

The thickness of the Pd layer deposited on the glass plate (i.e. the reference material) was determined by reflectometry using a Bruker-AXS D8-Discover diffractometer. The Pd deposition rate was calculated from this value, as well as the amount of palladium deposited over the entire outer surface of the membrane. Due to the dimensions of the sputtering chamber the maximum membrane length that can be used was $110 \mathrm{~mm}$.

\subsubsection{Preparation of mixed double active phases (palladium-metal oxide) membranes}

Other series of CMRs were prepared by impregnation of metal oxide precursor solutions followed by an activation procedure (calcinations at $400^{\circ} \mathrm{C}$ ). Thereafter the Pd was deposited by sputtering as described above in Section 2.2.1. The precursors for the first step were as follow: $\mathrm{Ce}\left(\mathrm{NO}_{3}\right)_{3}$ (Aldrich), $\mathrm{FeCl}_{3}$ (Sigma Aldrich) and $\mathrm{Cu}\left(\mathrm{NO}_{3}\right)_{2}-6 \mathrm{H}_{2} \mathrm{O}$ (Aldrich). The amount of metal oxides loaded into the membranes was calculated by the weight differences.

\subsubsection{Preparation of palladium sputtered corundum}

Due to the small amount of palladium deposited on the membrane by sputtering it was not possible to detect and characterize it by the techniques used. In order to increase the relative amount of Pd with respect to the support, a corundum powder was used. The pretreatment procedures were the same as for the membranes. A fine layer of powder was distributed onto a glass plate and introduced in the vacuum vessel of the sputtering apparatus. The Pd was sputtered in the same conditions as on the membranes. The post treatment of the powder was the same as for the membranes.

\subsection{Characterization of the catalytic membrane reactors}

The bulk and surface of the original and modified membranes were studied by environmental scanning electron microscopy (ESEM) (JEOL, JSM 6400 instrument) coupled with X-ray micro analyzer. The inner and outer surfaces of the membranes were also analyzed with ESEM in back scattering mode in order to determine the distribution of the active phases in the catalytic membrane reactors.

Microstructural characterization by transmission electron microscopy (TEM) and high resolution transmission electron microscopy (HRTEM) was performed at an accelerating voltage of $200 \mathrm{kV}$ in a JEOL 2010F instrument equipped with a field emission source. The point-to-point resolution was $0.19 \mathrm{~nm}$. No induced damage of the samples was observed under prolonged electron beam exposure. Samples were dispersed in alcohol in an ultrasonic bath, and a drop of supernatant suspension was poured onto a holey carbon-coated grid.

$\mathrm{X}$-ray reflectometry analysis was performed over the reference material coated with thin layer of Pd using a Bruker-AXS D8-Discover diffractometer with a parallel incident beam (Göbel mirror) and a vertical $\theta-\theta$ goniometer, a XYZ motorized stage mounted on an Eulerian cradle, incident and diffracted beam Soller slits, a $0.01^{\circ}$ receiving slit and a scintillation counter as a detector. The angular $2 \theta$ diffraction range was between 0.4 and $5^{\circ}$. The data were collected with an angular step of $0.004^{\circ}$ at $10 \mathrm{~s}$ per step. $\mathrm{Cu}_{\mathrm{k} \alpha}$ radiation was obtained from a copper X-ray tube operated with variable voltage and current.

$\mu$-XRD analysis was performed over the four types of CMRs prepared using a Bruker-AXS D8-Discover diffractometer at the same conditions detailed elsewhere [19].

\subsection{Inductive coupled plasma analyses (ICP)}

Aliquot water samples were withdrawn from the reaction vessel at the end of the reactions. After proper drying and acid digestion the samples were analyzed for active phase leaching. A high resolution ICP-OES spectrometer (Spectro, model ARCOS FHS16) was used to determine the $\mathrm{Pd}, \mathrm{Ce}, \mathrm{Fe}, \mathrm{Cu}$ and $\mathrm{Ti}$ leaching from the CMRs during the hydrogen peroxide generation reaction as well as during the oxidation reaction.

\subsection{Temperature programmed desorption equipment coupled to mass detector analyzer}

The samples of sputtered Pd over corundum powder were studied by programmed desorption experiments. The procedure followed was similar to that applied for the membranes. The samples were calcined and activated in hydrogen flow in a similar way as the membrane reactors. A TPDRO (Thermo, TPD/R/O 1100) coupled to mass detector (Pfeiffer vacuum, Omnistar ${ }^{\mathrm{TM}}$ ) was used to determine the hydrogen adsorption capabilities of the samples in conditions similar to the ones of the studied reaction as well as to obtain a more detailed understanding of the deactivation and activation of the sCMRs.

\subsection{Experimental setup}

The CMRs were tested in a semi batch mode as represented in Fig. 1 . The outer membrane diameter $(3 \mathrm{~mm})$ is similar to the $1 / 8$ inch. It has been used 1/8" SS 316L standard fitting material (Swagelok), the ferrules in contact to the membrane were Teflon made. In order to avoid $\mathrm{H}_{2}$ leakage under the Teflon ferrule a thin film of commercial sealing material (Loctite 596, Henkel) was laid on the membrane ends previous to the experiments. By the way about $1 \mathrm{~cm}$ of the membrane length did not participate in the reaction. In all cases these areas are taken into account when the calculations were made. Each catalytic membrane reactor was completely submerged in a vessel containing $100 \mathrm{~mL}$ of phenol solution (Panreac). Phenol solution (100 ppm) was prepared with Milli-Q water. One end of the CMR was tightly closed; meanwhile hydrogen was supplied from the other side at $6 \mathrm{NmL} \mathrm{min}^{-1}$ using a mass flow controller (MFC). The transmembrane pressure was also 


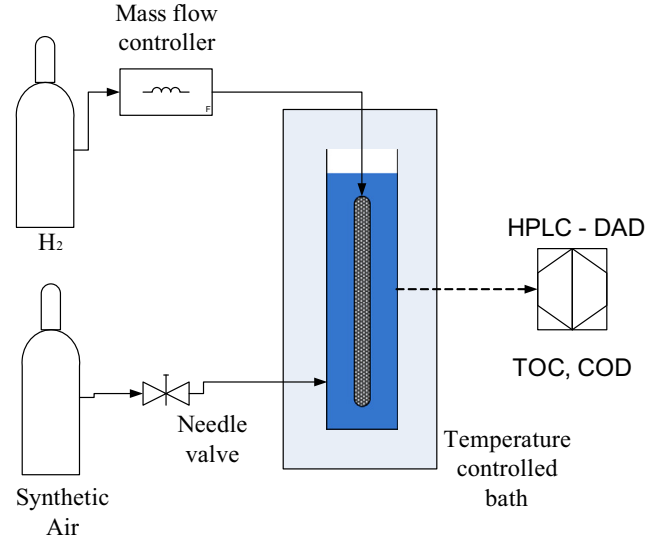

Fig. 1. Diagram of the experimental set-up used for semi batch phenol oxidation.

measured. The generation of hydrogen peroxide occurs on the external surface where the catalytic membrane is in contact with the liquid phase.

Synthetic air was pumped into the phenol solution and controlled by a needle valve. The air dosage was in the range of $100-200 \mathrm{sccm} / \mathrm{min}$. It was kept high in order to dissolve the maximum quantity of oxygen at atmospheric pressure. The reaction vessel was kept at constant temperature of $60^{\circ} \mathrm{C}\left( \pm 1^{\circ} \mathrm{C}\right)$ in a temperature controlled bath system.

The concentrations of phenol and the side products from the oxidation reaction were monitored with High Performance Liquid Chromatography (HPLC) (Shimadzu LC-2010) equipped with a diode array UV-vis detector (Shimadzu, SPD-M10Avp). A Varian OmniSphere C18 Column was used for separation of the products. The mobile phase was a mixture of Milli- $\mathrm{Q}$ water and acetonitrile (60:40) at $\mathrm{pH} 3.8$ adjusted by acetic acid. TOC measurements (Shimadzu, TOC-5000) as well as standard chemical oxygen demand analyses of the final and intermediate samples were performed.

Furthermore, all CMRs were tested for hydrogen peroxide generation following the procedure reported elsewhere [19]. This simple procedure was also used as an additional indicator for membrane alteration/deactivation e.g. it was carried out after the oxidation reaction had finished.

\section{Results and discussion}

\subsection{Catalytic membrane reactors prepared by impregnation method}

The catalytic membrane reactors prepared by impregnation were already described in our previous work [19]. In the cited work their activities in generating hydrogen peroxide, as well as the mechanism of the active phase deactivation were thoroughly discussed. They are resumed in the Table 1. In all experiments the transmembrane pressures were near to the bubble point taking into account that the hydrogen released from the membrane as gas is wasted.

\subsection{Catalytic membrane reactors prepared by sputtering method}

The proposed method allows to incorporate the Pd over the outer surface of the CMR and at the same time to reduce the amount of the costly metal considerably. The metal oxide phase was introduced previous to the Pd sputtering by impregnation of the precursor solution followed by calcinations. The prepared sCMRs are resumed in Table 1.

The thickness of the Pd layer on the surface of the glass plate was measured by a reflectometry technique and calculated from the X-ray reflectogram by a fast Fourier transform (FFT) method. The deposition rate under the chosen conditions was calculated from the thickness of the Pd layer on the surface of the glass plate. The deposition rate in all cases was $14.7 \mathrm{~nm} \mathrm{~min}{ }^{-1}$. In the case of sCMR11 the coating protocol was changed, so that instead of $90 \mathrm{~s}$ the membrane was placed into the chamber for $60 \mathrm{~s}$; the amount of Pd was nearly half that of the other sCMRs.

After sputtering, Pd was proven not to have any activity in the studied reaction which indicates that there is no hydrogen activation. So, after the sputtering procedure the catalytic membrane reactors were calcined at $400{ }^{\circ} \mathrm{C}$ during $6 \mathrm{~h}$ followed by an activation step in flowing hydrogen at $350^{\circ} \mathrm{C}$ for $2 \mathrm{~h}$ and finally cooled down in inert atmosphere (argon or helium) to ambient temperature. On the other hand it has been observed that in the experiments performed without any sCMRs pretreatment, Pd leaches into the water phase probably due to disaggregation from the membrane. After the calcination-reduction steps no palladium leaching to the liquid has been detected.

Table 1

Summary of the results for hydrogen peroxide generation obtained for the different catalytic membrane reactors.

\begin{tabular}{|c|c|c|c|c|c|c|}
\hline CMR & $\begin{array}{l}\text { Initial filtration pore size } \\
(\mathrm{nm})\end{array}$ & Active phase & $\begin{array}{l}\mathrm{H}_{2} \mathrm{O}_{2} \text { generation rate } \\
\left(\mathrm{mol} \mathrm{h}^{-1} \mathrm{~m}^{-2}\right)\end{array}$ & $\begin{array}{l}\text { Efficiency } \\
(\%)\end{array}$ & $\begin{array}{l}\text { Max. } \mathrm{H}_{2} \mathrm{O}_{2} \text { generated } \\
(\mathrm{ppm})\end{array}$ & $\begin{array}{l}\text { Productivity }\left(\mathrm{mol} \mathrm{H}_{2} \mathrm{O}_{2} /\right. \\
(\mathrm{mmol} \mathrm{Pd} \mathrm{h}))\end{array}$ \\
\hline CMR1 & 4 & $1.1 \% \mathrm{Pd}$ & 6.7 & 34 & 47 & 0.072 \\
\hline CMR2 & 20 & $0.8 \% \mathrm{Pd}$ & 3.2 & 15 & 27 & 0.034 \\
\hline CMR3 & 100 & $0.9 \% \mathrm{Pd}$ & 2.8 & 14 & 26 & 0.027 \\
\hline CMR4 & 500 & $0.8 \% \mathrm{Pd}$ & 2.8 & 14 & 19 & 0.030 \\
\hline CMR5 & 1400 & $1.0 \% \mathrm{Pd}$ & 2.4 & 12 & 14 & 0.021 \\
\hline CMR6 & 200 & $\begin{array}{l}1.2 \% \mathrm{Pd}-1.3 \% \mathrm{CeO}_{2}-1.5 \% \\
\mathrm{Fe}_{2} \mathrm{O}_{3}\end{array}$ & 9.7 & 34 & 57 & 0.085 \\
\hline CMR7 & 200 & $1.2 \% \mathrm{Pd}-\mathrm{CuAl}_{2} \mathrm{O}_{4}$ & 2.1 & 8 & 16 & 0.020 \\
\hline CMR8 & 800 & $1.1 \% \mathrm{Pd}-2.7 \% \mathrm{Fe}_{2} \mathrm{O}_{3}$ & 1.4 & 8 & 11 & 0.018 \\
\hline CMR9 & 500 & $1.4 \% \mathrm{Pd}-1.5 \% \mathrm{TiO}_{2}$ & 5.6 & 19 & 13 & 0.059 \\
\hline CMR10 & 4 & No active phase & 0 & 0 & 0 & 0 \\
\hline sCMR11 & 20 & $0.003 \% \mathrm{Pd}$ & 13.7 & 64 & 70 & 50.374 \\
\hline sCMR12 & 100 & $3 \% \mathrm{CeO}_{2}-0.005 \% \mathrm{Pd}$ & 1.9 & 8 & 16 & 4.657 \\
\hline sCMR13 & 100 & $2 \% \mathrm{Fe}_{2} \mathrm{O}_{3}-0.005 \% \mathrm{Pd}$ & 0.6 & 2 & 3 & 1.471 \\
\hline sCMR14 & 100 & $\mathrm{CuAl}_{2} \mathrm{O}_{4}-0.005 \% \mathrm{Pd}$ & 3 & 13 & 14 & 7.354 \\
\hline sCMR15 & 200 & $\begin{array}{l}1.3 \% \mathrm{CeO}_{2}-1.5 \% \mathrm{Fe}_{2} \mathrm{O}_{3}- \\
0.005 \% \mathrm{Pd}\end{array}$ & 2.2 & 9.4 & 19 & 5.393 \\
\hline
\end{tabular}

The $\mathrm{H}_{2} \mathrm{O}_{2}$ generation rates are apparent, i.e. hydrogen peroxide decomposition is not taken into account. 


\subsection{Environmental scanning electron microscopy}

The Fig. 2 shows the surface of the catalytic membrane reactor after the sputtering and calcination-reduction steps. As can be seen no structural differences are observed compared with the original membrane. It should be mentioned that the resolution of the microscope does not permit to detect the palladium grains on the surface. Fig. 3 is an image of the surface of the same membrane, obtained using a detector sensitive to the back scattered electrons. It is practically impossible to distinguish individual Pd grains on the surface, a fact that confirms that the costly metal is finely dispersed on the surface.

The EDX analysis performed with ESEM demonstrated that the Pd is selectively deposited over the external surface of the membrane. In the Fig. 4 can be seen the cross sectional distribution of the Pd. It is located on the outer surface ( $10 \mu \mathrm{m}$ in depth) of the membrane, and no metal penetration into the membrane bulk was detected.

The main advantages achieved in the preparation of the sCMRs by the sputtering method are in reducing of the amount of noble metal (around 200 times in the present study) compared with the CMR prepared via impregnation. Additionally, it is expected that the formation of very small grains of palladium over the membrane surface (in the form of finely dispersed palladium) will

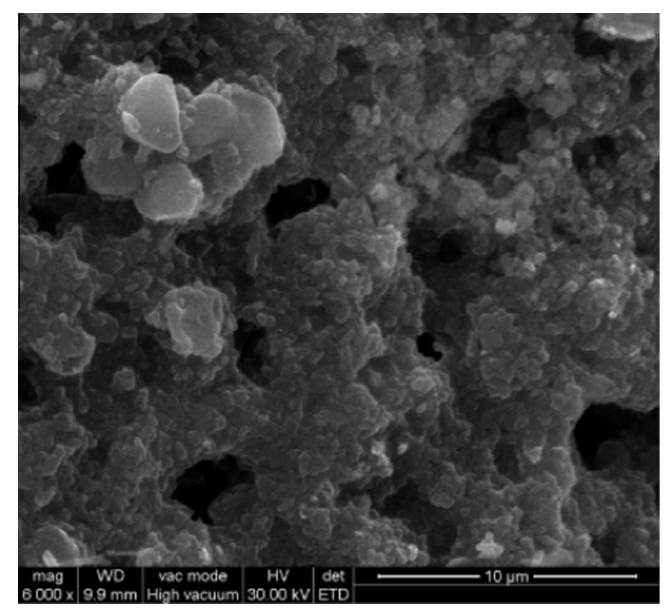

Fig. 2. Environmental scanning electron microscopy image of the outer surface of the sCMR11.

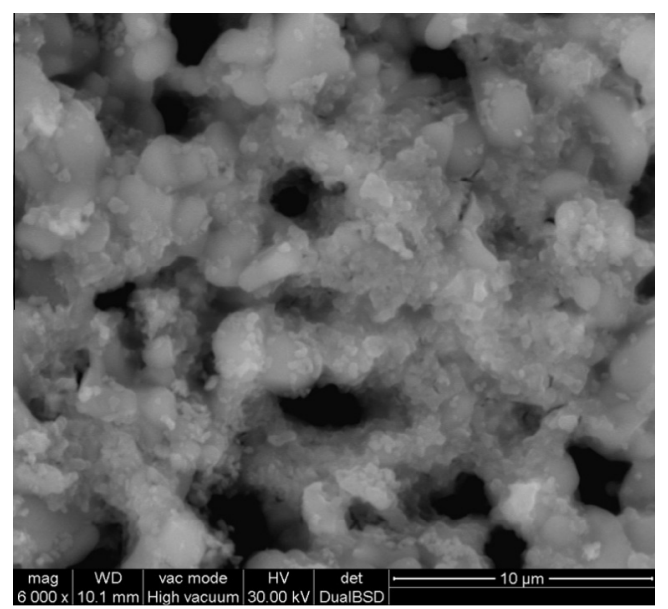

Fig. 3. ESEM in backscattering mode of catalytic membrane reactor sCMR11.

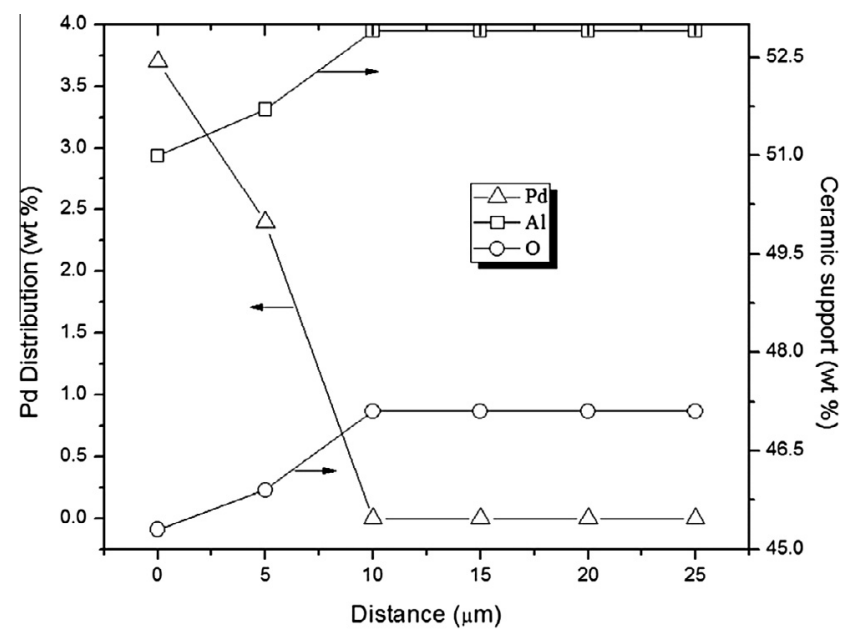

Fig. 4. EDX analysis of sputtered Pd through the cross section of CMR.

increase considerably the catalytic activity of these catalytic membrane reactors.

The chemical micro analysis capability of the ESEM was also used in order to check for presence of carbonaceous compounds on the surface of the used in the oxidation reaction catalytic reactors. It has not been detected any carbon presence on the surface so we discard the possibility that the phenol, TOC and COD elimination are due to adsorption-condensation reactions on reactor surface.

\subsection{X-ray diffraction analysis}

The XRD analysis of SCMR11 was performed with an acquisition time of $300 \mathrm{~s}$ per each step; however, the signal of the palladium phase was not detected. The acquisition time was increased to $900 \mathrm{~s}$ per frame with no detection of Pd signal. We consider that the main reason for the absence of palladium signal is due to the Pd grain size. Despite the high concentration of Pd on the outer surface of the catalytic membrane reactor, it is believed that the Pd particles are extremely small, below of the detection limit.

The $\mu$-XRD analysis performed for sCMR12 to sCMR15 reveal the presence of Pd crystals over the outer surface of the catalytic membrane. Fig. 5 presents a diffractogram for the catalytic membrane reactor containing a mixture of cerium oxide and sputtered palladium. The analysis was carried out for $900 \mathrm{~s}$ in order to detect a Pd signal in the specific $2 \theta$ angles. Cerium oxide was detected at $2 \theta$ angles of $28.62,33.15,47.58$ and $56.45^{\circ}$ in correspondence with ICDD data file 03-065-5923. Despite the large acquisition time at the specific $2 \theta$ angles, a Pd phase is difficult to confirm. This outcome is expected due to the small amount of Pd as well as the very small crystal size.

\subsection{Leaching of Pd during the hydrogen peroxide generation}

For the two types of catalytic membrane reactors, obtained by impregnation and by sputtering, the presence of palladium in the water during the hydrogen peroxide generation was checked using ICP analysis. CMRs produced by sputtering were tested in the $\mathrm{H}_{2} \mathrm{O}_{2}$ generation just after the Pd was sputtered and showed about $30 \%$ leaching of Pd into the solution. Due to the poor adhesion onto the membrane surface it is believed that sputtered Pd is removed from the surface by the gas exerting pressure from the inner side. When calcination followed by reduction steps were performed on the sCMRs after the sputtering process no furthermore Pd leaching 


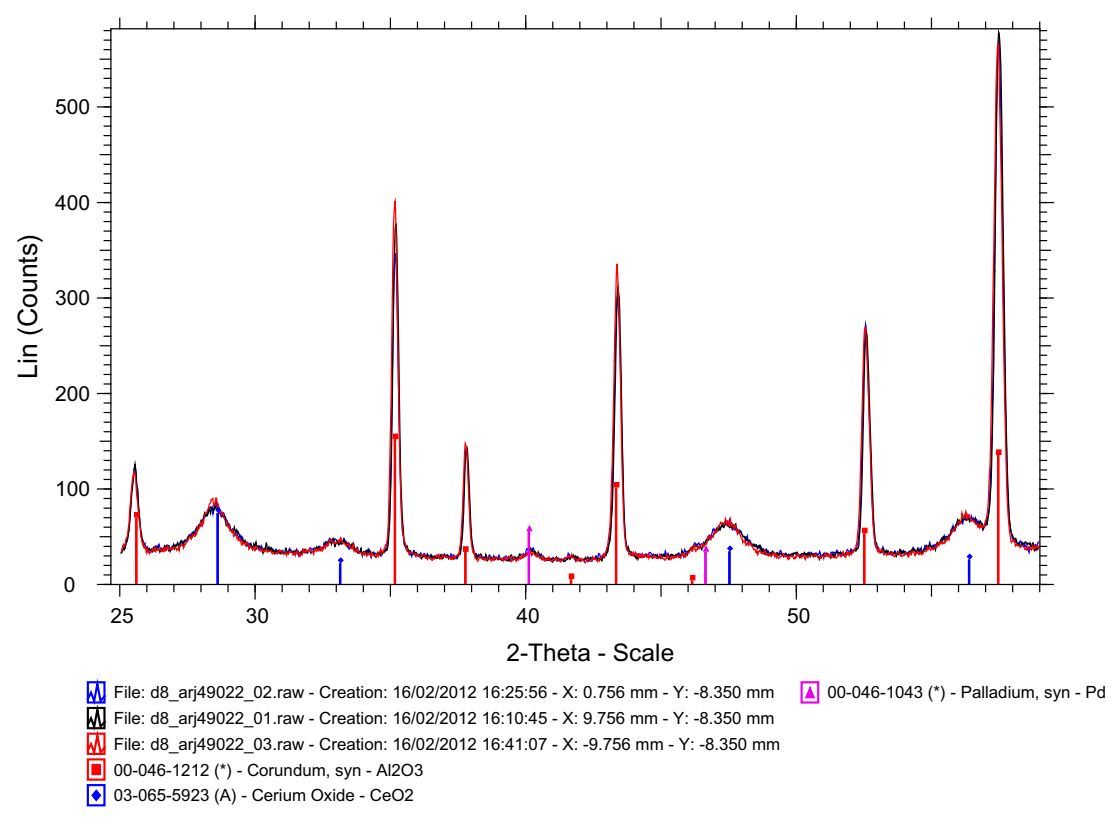

Fig. 5. $\mu-X R D$ analysis performed for sCMR12.
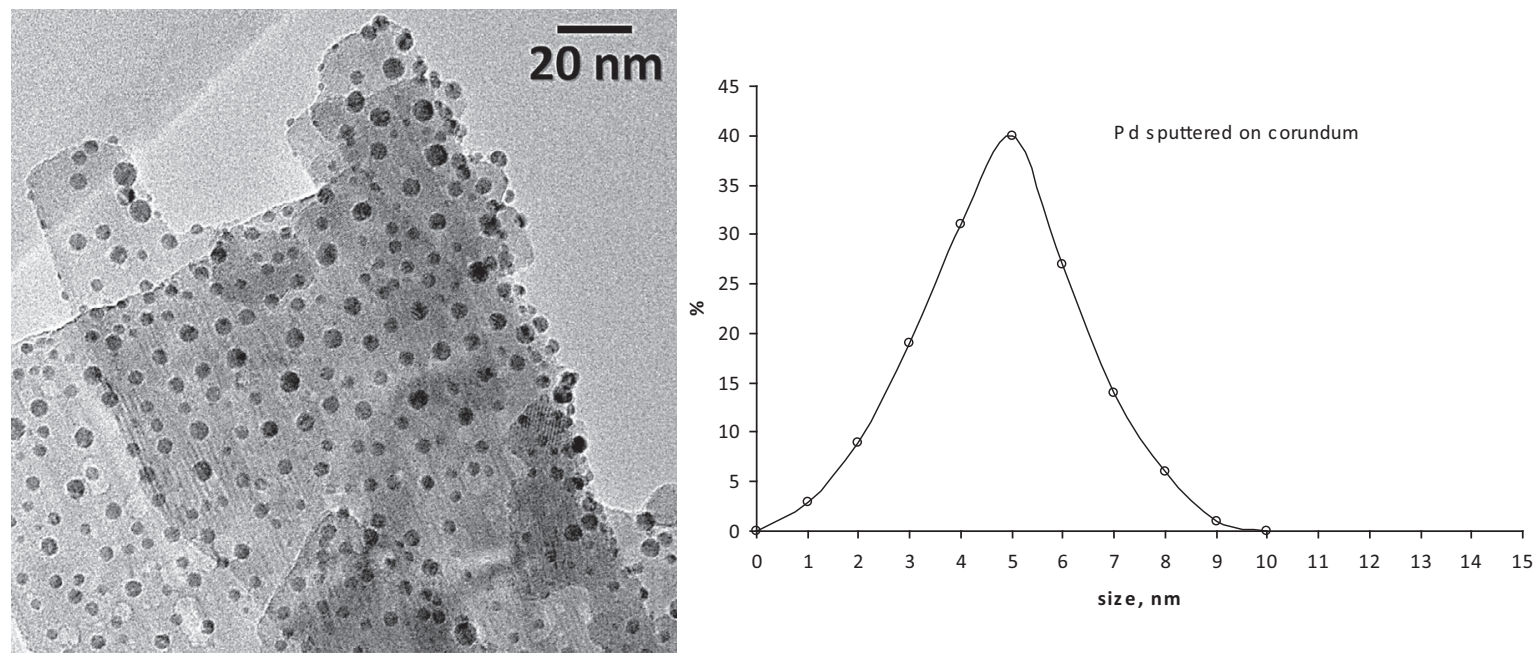

Fig. 6. TEM image of Pd particles on corundum powder after sputtering and particle size distribution.

was detected in the liquid phase. For membranes with impregnated palladium no leaching of precious metal was observed.

\subsection{TEM of corundum powder with sputtered palladium}

Low magnification bright-field TEM images have been recorded in order to determine the mean particle size of the Pd particles (more than 200 particles have been measured). A representative example of such images is shown in Fig. 6. In all cases Pd particles are very well dispersed over the alumina support and no agglomerates have been detected, thus confirming that the sputtering method leads to a high Pd dispersion. The mean particle size of Pd particles is centered at $4.8 \mathrm{~nm}$, being $95 \%$ of particles within the $2-7 \mathrm{~nm}$ range. Fig. 6 presents a representative picture of the obtained images as well as the particle size distribution graph.

As expected, the particles are very small and are in the nanoscale range. These sizes are in agreement with the calculations made from the thickness of the Pd layer on the glass plate obtained by reflectometry.

\subsection{Catalytic activity of CMRs}

\subsubsection{Hydrogen peroxide generation}

Different configurations to supply synthetic air and hydrogen were used. In the first configuration a mixture of oxygen and hydrogen was fed through the membrane channel. The ratios of synthetic air to hydrogen mixtures were kept below the explosive limit. Under this experimental setup null generation of $\mathrm{H}_{2} \mathrm{O}_{2}$ was obtained; this behavior is related to the oxidation state of the supported palladium on the catalytic membrane reactor [21]. At higher concentration of synthetic air there is a considerable increase of the ratio $\mathrm{Pd}^{2+} / \mathrm{Pd}^{0}$, therefore the deactivation of CMR is related to the oxidation of the palladium surface where hydrogen cannot be activated. This effect was also observed in the 
synthesis of hydrogen peroxide with catalytic membrane reactors done by Pashkova et al. [16]. These findings were confirmed by experiments carried out in the opposite conditions, working above the flammability limit (flammability range 4-74 $\mathrm{H}_{2} / \mathrm{air}, \mathrm{v} / \mathrm{v} \%$ ). In this case there was hydrogen peroxide production. The excess of hydrogen maintained the Pd in reduced state that is essential for the hydrogen activation. Therefore this configuration was discarded due to the low efficiency of the hydrogen use.

It has been decided to introduce the $\mathrm{H}_{2}$ and the synthetic air separately. Hydrogen was supplied with a mass flow controller through the membrane channel. The $\mathrm{H}_{2}$ flew throughout the membrane wall to the palladium particles in the reaction zone on the outer membrane surface. Meanwhile synthetic air was bubbled into the batch vessel. With this assembly different advantages are achieved, e.g. the Pd is protected from surface oxidation and the hydrogen dosage can be controlled very precisely in order to use it entirely in the reaction.

The following Table 1 presents the results obtained for hydrogen peroxide generation. The results for the membranes obtained by Pd impregnation have been presented in our previous work [19] and here are presented for clarity and comparison.

The results in Table 1 can be divided into two groups. The first one consists of the catalytic membrane reactors that were prepared by conventional impregnation techniques, CMR1 to CMR9 and the second group comprises the reactors in which the palladium was introduced by sputtering, from sCMR11 to sCMR15. There is also a blank membrane reactor for which no active phases were introduced, CMR10.

$\mathrm{H}_{2} \mathrm{O}_{2}$ generation rates were calculated from the initial peroxide generation rates assuming that the decomposition rate of generated hydrogen peroxide over the active noble metal surface in the beginning is very low. In our previous work the calculation procedures as well as the initial considerations are discussed in more details [19].

In all cases a maximum value of the hydrogen peroxide concentration in the solution is reached. We demonstrated in our previous work that, at this concentration, the palladium is deactivated by surface oxidation [19]. It is important to note that the activity can be recovered quite simply by just taking out the membrane from the water and leaving the hydrogen flowing through the membrane for a while at ambient temperature. If the membrane is then submerged in the water, an increase in the hydrogen peroxide concentration is observed. If the water in the reaction vessel is exchanged, the results are exactly the same as when using a fresh solution.

The results for hydrogen peroxide generation obtained for membranes with sputtered palladium are summarized in the second part of Table 1 . In the case of sCMR 11 which contained only $\mathrm{Pd}$, the measured values were markedly higher than for all other catalytic membrane reactors. The rate of hydrogen peroxide generation is twice that for CMR1, the reactor with higher generation rate from the impregnated ones. The rest of the palladium sputtered catalytic membrane reactors present quite similar results to those for the impregnated ones. This is an indication that the main part of the palladium in the impregnated membranes is not involved in the reaction. The main role of the noble metal in the studied reaction is the hydrogen activation that occurs on the metallic surface. A relatively high degree of metal dispersion is achieved in the sputtered membranes that it is translated into very high activity for hydrogen peroxide generation compared to the impregnated membranes. In the last column of Table 1 the activities for hydrogen peroxide generation are normalized with respect to the palladium content. A comparison between CMR2 and sCMR11 (both of them with the same $20 \mathrm{~nm}$ pore size supporting membrane) shows a very significant difference: the sputtered membrane has almost 1500 times higher activity. In all other cases there are large differences as well. The second active phases for sputtered membranes were the same as for the impregnated ones. $\mathrm{TiO}_{2}$ was not used due to its very low activity in the studied oxidation reaction as discussed in the next sections. The interference that these second phases could have on the results reported in Table 1 is unknown at this stage.

Once the maximum level of hydrogen peroxide in the solution was reached the Pd sputtered catalytic membrane reactors were deactivated as in the case of the impregnated ones. It is reasonable to suppose that deactivation is due to the surface oxidation of Pd similarly to the impregnated membranes. This process is probably even faster due to the higher dispersion of palladium. Following this considerations the reactors should be easily re-activated in contact with hydrogen as in the previous case. Surprisingly after applying this simple procedure of hydrogen flowing through the membranes they were not active in the studied reaction. The membranes were reduced by flowing hydrogen in a continuous reactor at different temperatures, up to $400{ }^{\circ} \mathrm{C}$. The cooling step was performed by hydrogen or an inert gas. In both cases the membranes remained inactive after this procedure. In order to re-activate the membranes it was necessary to calcined them in air at $400{ }^{\circ} \mathrm{C}$, reduce by hydrogen at $400^{\circ} \mathrm{C}$ and cool in an inert atmosphere. Thereafter the membranes presented exactly the same activities for hydrogen peroxide generation. All experiments were carried out in MilliQ water; no chemicals have been added to the experimental setup except the high purity hydrogen and air. Chemical contaminations that require oxidation were discarded as a possible cause for the deactivation. These results suggest that in addition to the surface passivation of the palladium there are additional changes in the noble metal. It may be assumed that hydrogen has an additional effect which is difficult to clarify by directly investigating the catalytic membrane reactors. We discuss this issue in the section where temperature programmed desorption results for palladium sputtered on corundum powder are presented.

\subsubsection{Phenol oxidation with catalytic membrane reactors prepared by impregnation}

The catalytic membrane reactors with only palladium as active phase (CMR1 to CMR5) did not present any appreciable activity in the phenol oxidation reaction. Fig. 7 presents the results for CMR1 at different reaction temperatures. Additionally, the results for a blank test, CMR10 (no active phase), are included. In this case the experimental conditions were maintained and the test was

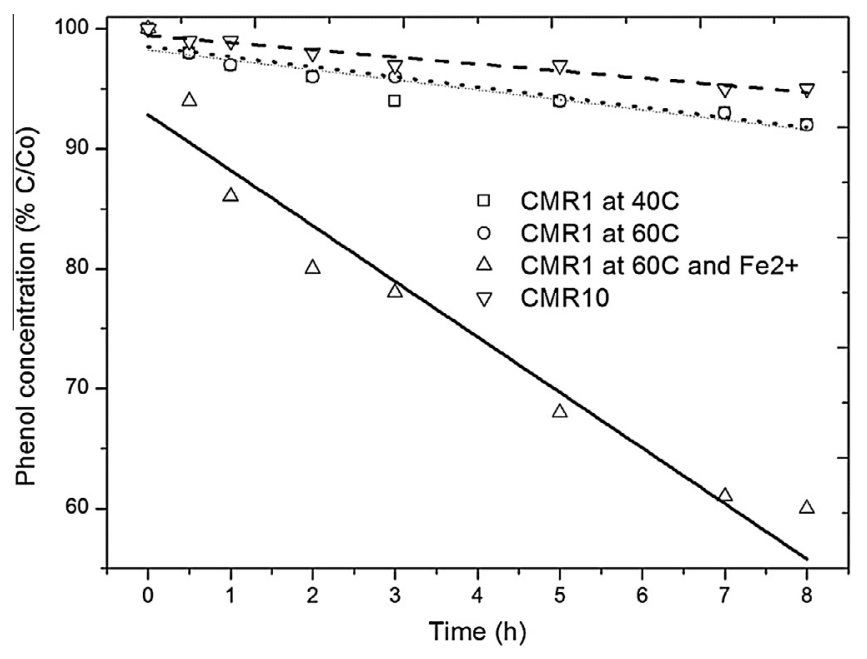

Fig. 7. Phenol oxidation with CMR1. 
performed in order to verify if any stripping of the phenol occurs at the reaction temperature. It can be seen that the concentration of phenol decreases about $5 \%$ in $8 \mathrm{~h}$ at both temperatures. This value is quite similar to the result of the blank test so the apparent activity can be attributed to the phenol stripping.

These results clearly indicate that in the studied case the palladium is not active in the reaction of generation of hydroxyl radicals. They also confirm that the most likely reaction pathway consists of hydrogen activation on Pd surface followed by a reaction between oxygen and activated hydrogen to form hydrogen peroxide or water. In this case the palladium becomes deactivated when certain peroxide concentration is reached. A second active phase in the catalytic membrane reactors is needed in order to generate hydroxyl radicals active in the further oxidation of organic matter present in the water. This reaction should be faster than the peroxide generation itself in order to protect the palladium. The validity of the above statement was checked by a simple experiment. Previous to the insertion of the catalytic membrane reactor in the reaction vessel, a $\mathrm{Fe}^{2+}$ salt had been added to the phenol solution. The results for the CMR1 are presented in Fig. 7. As can be seen the phenol concentration decreases by about $40 \%$ within $8 \mathrm{~h}$ of reaction. In the presented case the phenol elimination coincides with the TOC and COD decrease. It is important to note that the results of the phenol elimination depend linearly on time. This suggests a first-order reaction with respect to hydrogen peroxide generation, e.g. the phenol oxidation is the faster reaction.

The calculated rate of phenol oxidation is $0.05 \mathrm{mmol} \mathrm{h}^{-1}$ assuming a linear dependence in the case of CMR1 in the presence of $\mathrm{Fe}^{2+}$. The normalized value for hydrogen peroxide generation for the CMR1 presented in Table 1 is $6.7 \mathrm{~mol} \mathrm{H}_{2} \mathrm{O}_{2}\left(\mathrm{~h} \mathrm{~m}^{2}\right)^{-1}$ which corresponds to $5.5 \mathrm{mmol} \mathrm{h}^{-1}$ reactor $^{-1}$. A comparison of these values suggests that about $10-15 \%$ of the generated peroxide is directly involved in the organic oxidation. The results therefore are not very far from the recommended conditions for the Fenton reaction where usually an oxidant excess of about 3-5 times with respect to the organic matter is considered [7]. The efficiency is calculated as

$\mathrm{E}=\left(\mathrm{H}_{2} \mathrm{O}_{2 \mathrm{r}} / \mathrm{H}_{2} \mathrm{O}_{2 \mathrm{p}}\right) * 100$

$\mathrm{C}_{6} \mathrm{H}_{6} \mathrm{O}+14 \mathrm{H}_{2} \mathrm{O}_{2} \rightarrow 6 \mathrm{CO}_{2}+17 \mathrm{H}_{2} \mathrm{O}$

where $\mathrm{H}_{2} \mathrm{O}_{2 \mathrm{r}}$ is the required hydrogen peroxide to achieve complete mineralization of phenol and $\mathrm{H}_{2} \mathrm{O}_{2 p}$ is the theoretical amount of hydrogen peroxide generated with the catalytic membrane reactor using the kinetic rate calculated per every CMR.

As mentioned before, the experiments performed with CMR1 to CMR5 demonstrate that the presence of a second active phase in the reactors is required to ensure catalytic activity in the Fenton reaction.

Different heterogeneous active phases are reported in the literature to be active in the reaction of hydroxyl radical generation from hydrogen peroxide [22]. In the present study we chose $\mathrm{Fe}_{2} \mathrm{O}_{3}, \mathrm{CuAl}_{2} \mathrm{O}_{4}, \mathrm{TiO}_{2}$ and $\mathrm{CeO}_{2}$.

Fig. 8 presents the results for the phenol oxidation when the catalytic membrane reactors with second active phases $\mathrm{Cu}_{2} \mathrm{AlO}_{4}$ (CMR7), $\mathrm{Fe}_{2} \mathrm{O}_{3}$ (CMR8) and $\mathrm{TiO}_{2}$ (CMR9) were used. Despite the high activity of CMR9 for hydrogen peroxide generation, no detectable activity was observed for phenol oxidation. The results indicate that $\mathrm{TiO}_{2}$ in this case is not active in generating hydroxyl radicals that subsequently would oxidize the phenol. More detailed studies should be performed in order to elaborate a plausible explanation in this particular case.

As seen in Fig. 8 and 15\% of phenol elimination was reached with CMR7. The phenol mineralization monitored by TOC analysis was $5 \%$. In this case no aromatic compounds were detected as intermediates in the HPLC chromatograms, and all signals detected

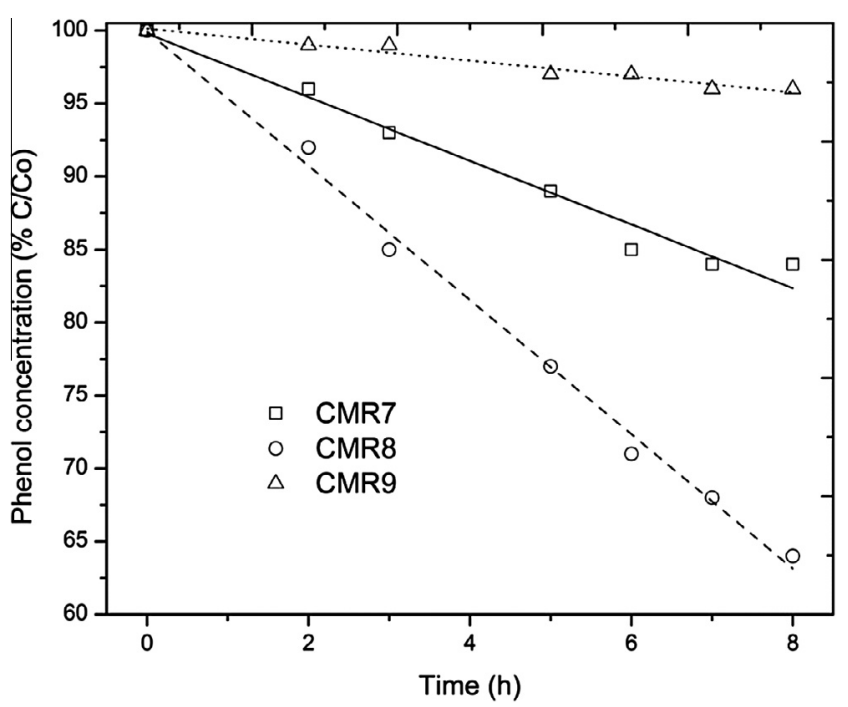

Fig. 8. Phenol degradation with CMR7, CMR8 and CMR9.

corresponded to low molecular organic acids. At this low concentration it was difficult to identify clearly the exact compounds.

CMR8 presented a higher activity in phenol abatement. Compared to the $\mathrm{CuAl}_{2} \mathrm{O}_{4}$-Pd membrane, this catalytic membrane reached $36 \%$ of phenol degradation. In this case, a small amount of catechol (less than $5 \mathrm{ppm}$ ) was identified in the reaction products along with traces of low molecular organic acids. A mineralization of $25 \%$ was reached after TOC measurements.

Fig. 9 presents the results for the phenol oxidation obtained with CMR6. In this case previous to the palladium load iron and cerium oxides were introduced to the membrane.

The CMR catalytic redox properties are improved by the interaction between metallic palladium and cerium oxide, since the oxygen storage capacity of cerium oxide provides oxygen mobility in the membrane active phase [23]. In addition, E.G. Heckert et al. have observed that cerium oxide redox capacity $\left(\mathrm{Ce}^{3+}-\mathrm{Ce}^{4+}\right)$ enhances the catalytic activity of cerium oxide to act like a hydroxyl radicals generator from hydrogen peroxide [24]. The analogous Fenton/Haber Weiss reaction with cerium oxide are:

$\mathrm{Ce}^{3+}+\mathrm{H}_{2} \mathrm{O}_{2}+\mathrm{H}^{+} \rightarrow \mathrm{Ce}^{4+}+\mathrm{OH}^{\cdot}+\mathrm{H}_{2} \mathrm{O}$

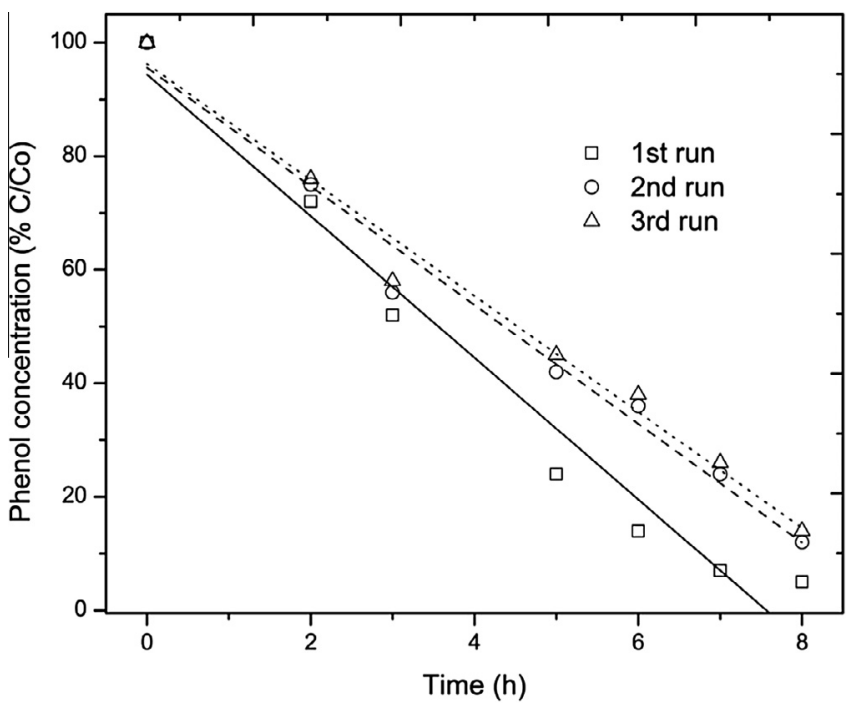

Fig. 9. Catalytic phenol oxidation with a Pd-cerium, iron oxides membrane reactor. 
$\mathrm{OH}^{\cdot}+\mathrm{H}_{2} \mathrm{O}_{2} \rightarrow \mathrm{HO}_{2}^{-}+\mathrm{H}_{2} \mathrm{O}$

$\mathrm{Ce}^{4+}+\mathrm{HO}_{2}^{-} \rightarrow \mathrm{O}_{2}+\mathrm{Ce}^{3+} \mathrm{H}^{+}$

The reaction temperature was maintained at $60^{\circ} \mathrm{C}$. This catalytic membrane reactor shows a high activity in phenol degradation, with a phenol abatement level of $93 \%$ after $7 \mathrm{~h}$ of reaction. No intermediates were detected in the analyzed samples by HPLC. The phenol was oxidized to carbon dioxide and water. This complete mineralization was confirmed by the TOC analyses of the samples as well as COD measurements. As in the previous cases the phenol oxidation is a first order reaction with respect to peroxide generation. In this case the efficiency of the hydrogen peroxide for phenol oxidation is about $35 \%$. This value was calculated as in the previous case and the ratio between phenol elimination $\left(0.13 \mathrm{mmol} \mathrm{h}^{-1}\right)$ to the peroxide generation for CMR6 from Table 1 is $5.5 \mathrm{mmol} \mathrm{h}^{-1}$ reactor $^{-1}$.

Once the reaction had finished, the phenol solution in the reaction vessel was renewed. As it can be seen from the experimental results presented in Fig. 9, the results obtained in the second run are the same as those in the first one. Several consecutive tests have been performed without any appreciable loss of catalytic activity. This is a very important feature of the developed catalytic membrane reactors that indicates that they can be used in a continuous operation.

In the open scientific literature there are reports dealing with phenol hydrogenation using palladium as a catalyst [25-28]. Under the experimental conditions of the present work we did not expect a similar reaction, but nevertheless a test was performed. CMR6 was used to determine possible phenol hydrogenation, and the experimental conditions were kept constant without air supply to the reaction vessel. No decrease in the phenol concentration was observed after $5 \mathrm{~h}$ of reaction.

\subsubsection{Phenol oxidation with catalytic membrane reactors prepared by the sputtering method}

The sputtering preparation techniques were aimed at reducing the amount of precious metal. High dispersion is achieved at the same time which also led to higher overall activity. The proposed method also allows the deposition of the Pd exclusively into the reaction zone of the studied reaction.

sCMR11 that contains only Pd as an active phase showed a similar behavior in the studied reaction as the Pd impregnated catalytic membrane reactors. SCMR11 did not present any activity for the phenol oxidation under the studied conditions. Similarly to the case of the impregnated membrane, $\mathrm{Fe}^{2+}$ salt was added to the phenol solution previous to the reaction. The presence of ferrous ions in the homogeneous phase improves the phenol oxidation up to $12 \%$ conversion. This value is very low considering the high activity of this reactor in peroxide generation (Table 1 ). Initially it was deduced that due to the high rate of hydrogen peroxide generation the oxidant was not consumed sufficiently fast in the phenol oxidation which would lead to peroxide accumulation in the solution resulting in palladium deactivation. Additional experiments presented below revealed that other reactions are involved in the palladium deactivation.

The surface passivation of Pd due to the slow decomposition of hydrogen peroxide to reactive hydroxyl radicals may induce the oxidation of the palladium surface and subsequent deactivation, as it was observed in the $\mathrm{H}_{2} \mathrm{O}_{2}$ generation by V.R. Choudhary et al. [29].

The rest of SCMRs were also tested for phenol degradation. The Fig. 10 shows the phenol abatement using these catalytic membrane reactors. The phenol reduction with sCMR12 and sCMR13 reached $15 \%$ after $8 \mathrm{~h}$ of reaction at $60{ }^{\circ} \mathrm{C}$. In both cases the oxidized phenol was completely mineralized, TOC reduction of $15 \%$.

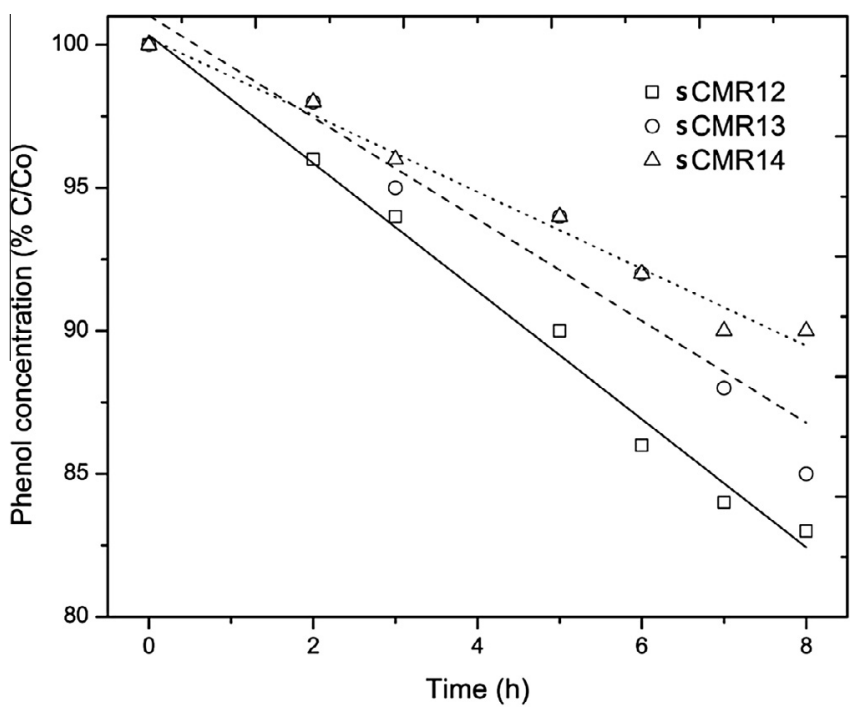

Fig. 10. Phenol degradation with sCMR12, sCMR13 and sCMR14.

sCMR14 with copper aluminate spinel presented quite a low activity, about $10 \%$ of phenol abetment and $6 \%$ of TOC reduction. Peaks of low intensities were detected by HPLC at retention times that correspond to the low molecular organics acids. The phenol oxidation reactions as in the previously presented cases are first order with respect to peroxide generation. The efficiencies of the hydrogen peroxide involved directly in the phenol oxidation are lower than for the impregnated catalytic membrane reactors. In consequent experiments these catalytic membrane reactors completely lost their activities in the studied reaction. As commented in Section 3.7.1, in order to re-activate the reactors it was necessary to calcined, reduce and cool them down in an inert atmosphere.

The activity for phenol elimination obtained for SCMR15 is presented in Fig. 11.

In the first test sCMR15 presented $42 \%$ of phenol elimination and no intermediate products were detected (TOC reduction of $42 \%$ was observed). Consequently, a second test was performed after changing the phenol solution in the reaction vessel. In this case the activity of the catalytic membrane reactor dropped to

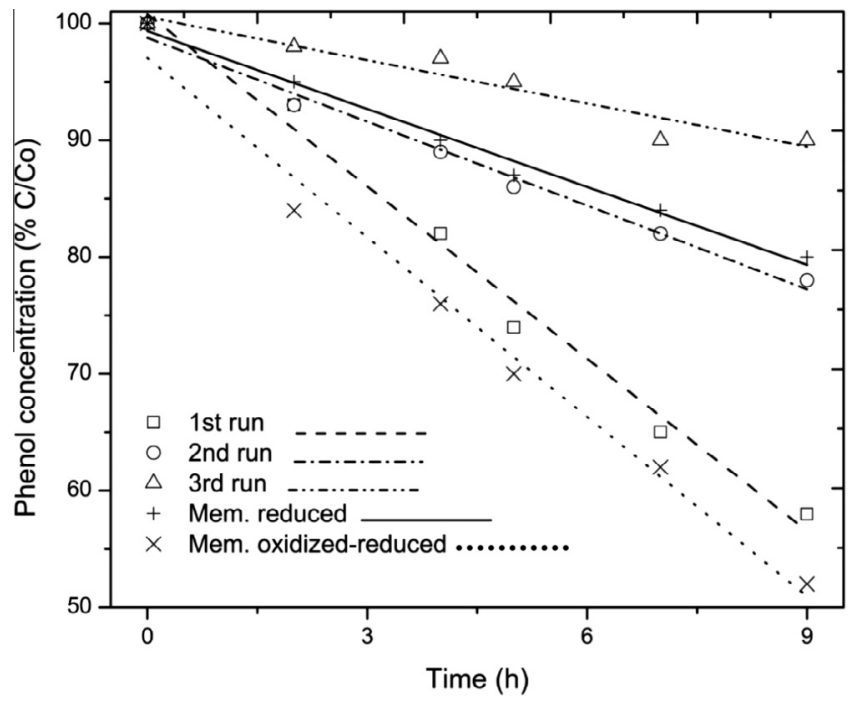

Fig. 11. Phenol oxidation using sCMR15 at different reaction temperatures and consecutive runs. 
$18 \%$ for phenol degradation and $10 \%$ for TOC elimination. In the third consecutive experiment insignificant activity was obtained and for both measured parameters, phenol and TOC, about 10\% of reduction was obtained. As commented before it was assumed that this decrease of activity is mainly due to the Pd deactivation. Taking into account the high dispersion of the Pd within the reaction zone it can be assumed that the hydrogen peroxide generation rate is significantly higher than the consumption of the oxidant in the subsequent reaction of phenol oxidation thus leading to increased levels of peroxide which passivates the noble metal. If this assumption is true, then the Pd activity in the studied reaction should be recovered after reduction in a hydrogen flow. However, after the reduction step at $400{ }^{\circ} \mathrm{C}$ in flowing hydrogen followed by a cooling step under inert atmosphere, the activity for the phenol oxidation barely reached $20 \%$.

The catalytic membrane reactor has been calcined in air atmosphere at $400{ }^{\circ} \mathrm{C}$ and thereafter reduced in $\mathrm{H}_{2}$ flow at $400{ }^{\circ} \mathrm{C}$, the cooling step was done in inert gas flow. As it can be seen from Fig. 11, the activity was recovered completely.

Despite of the high activities for hydrogen peroxide generation of the Pd sputtered catalytic membrane reactors compared to the impregnated ones there are some specific reactions which take place in the former case leading to the fast deactivation of the reactors. The small size of the palladium particles obtained after sputtering increases their activity but at the same time makes them more vulnerable to undesired reaction, e.g. palladium hydride formation.
It is important to mention that when the second active phase is cerium oxide the catalytic membrane reactor appears to possess a more stable activity compared to the other ones. A possible reason for this difference could be the specific interaction between the small palladium crystals and the surrounding ceria which can favor the stabilization of the metal [30-34]. Possible implications of this strong metal support interaction (SMSI) in the studied reaction have actually been investigated in a more detailed study.

The formation of palladium hydride is an important concern in the dense Pd membrane when used in gas mixtures separation or in hydrogenation reactions [35,36]. Its formation provokes mechanical damage of the membranes, they become brittle. In order to overcome the problems associated with the hydride formation the working temperature is maintained above certain level, e.g. $300{ }^{\circ} \mathrm{C}$ [36-38].

In the Pd assisted catalytic reactions, especially in hydrogenation processes, the formation of palladium hydride is not considered as a major factor that can alter the catalyst activity; on the contrary, in some studies it is considered a beneficial source of hydrogen $[39,40]$. Other authors suggest that the palladium hydride, especially after it is transformed to $\beta$-Pd, is a main cause for the Pd deactivation, e.g. in hydrogenation reaction $[41,42]$.

Generally the palladium deactivation is attributed to other undesired reactions such as coke formation, water condensation, sulfur and carbon monoxide presence [22,43].

According to works in the open scientific literature the absorption of hydrogen leads after some time to Pd phase change,

Table 2

TPD program and the aim of each step.

\begin{tabular}{|c|c|c|}
\hline Step & $T$, gas flows, time & Aim of the step \\
\hline 1 & $60{ }^{\circ} \mathrm{C}, 20 \mathrm{sccm}^{3} / \mathrm{min}, 5 \% \mathrm{H}_{2}$ in $\mathrm{Ar}, 2 \mathrm{~h}$ & Reduction of the $\mathrm{Pd}$, possible formation of $\beta$-Pc \\
\hline 2 & $60^{\circ} \mathrm{C}, 20 \mathrm{sccm}^{3} / \mathrm{min}, \mathrm{Ar}, 30 \mathrm{~min}$ & Purging the lines \\
\hline 3 & Heating ramp, $5^{\circ} \mathrm{C} \mathrm{min}^{-1}$ up to $400{ }^{\circ} \mathrm{C}, 30 \mathrm{~min}$ at $400{ }^{\circ} \mathrm{C} ; 20 \mathrm{sccm}^{3} / \mathrm{min}, \mathrm{Ar}$ & Desorption of the $\mathrm{H}_{2}$ from the $\beta$-Pd \\
\hline 4 & Cool down to $60{ }^{\circ} \mathrm{C}$ in $20 \mathrm{sccm}^{3} / \mathrm{min}, \mathrm{Ar}$ & Restore the initial state of the studied sample \\
\hline
\end{tabular}

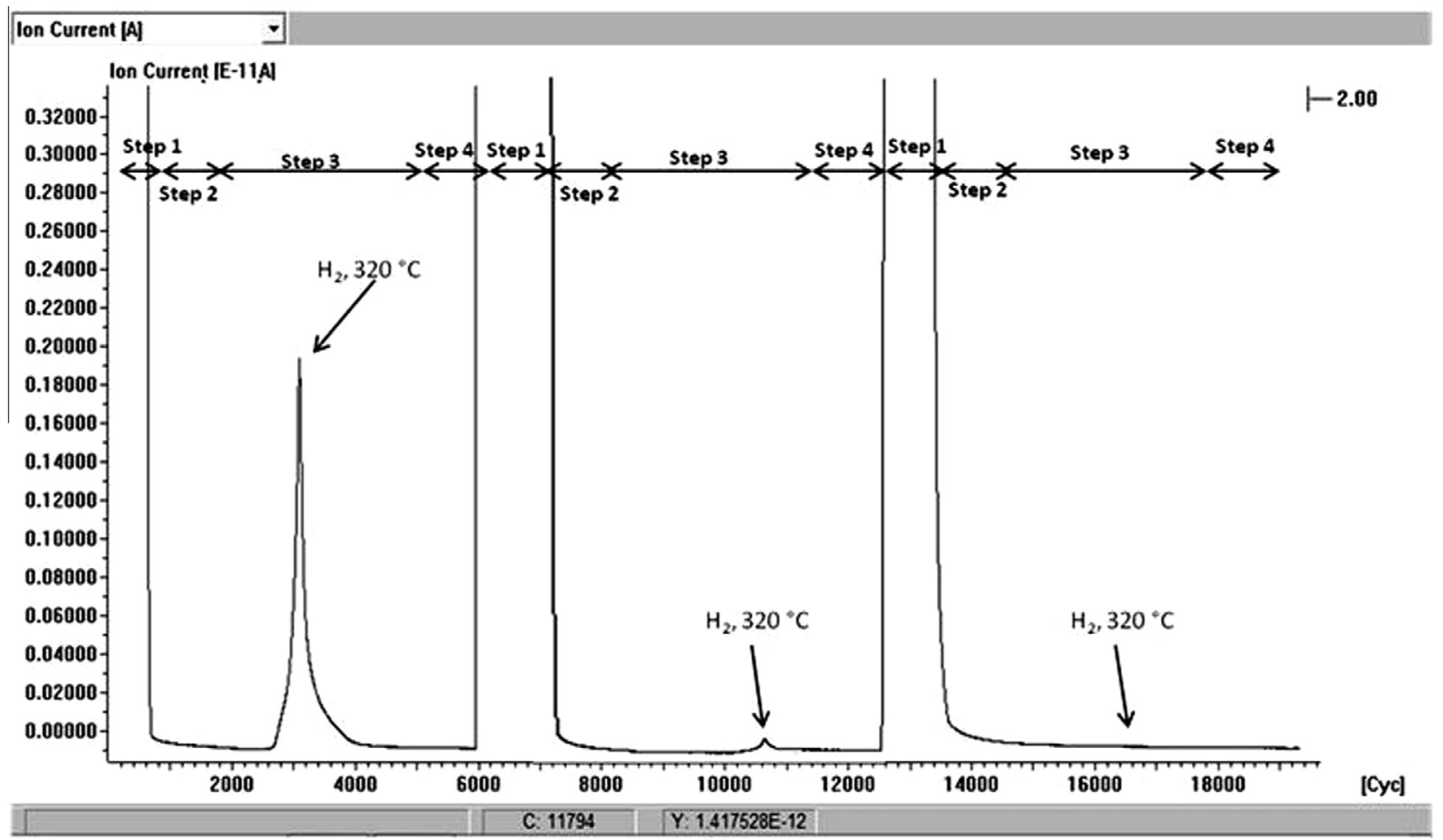

Fig. 12. TPD-MS $m / z=2$ signal obtained from Pd sputtered on corundum. 


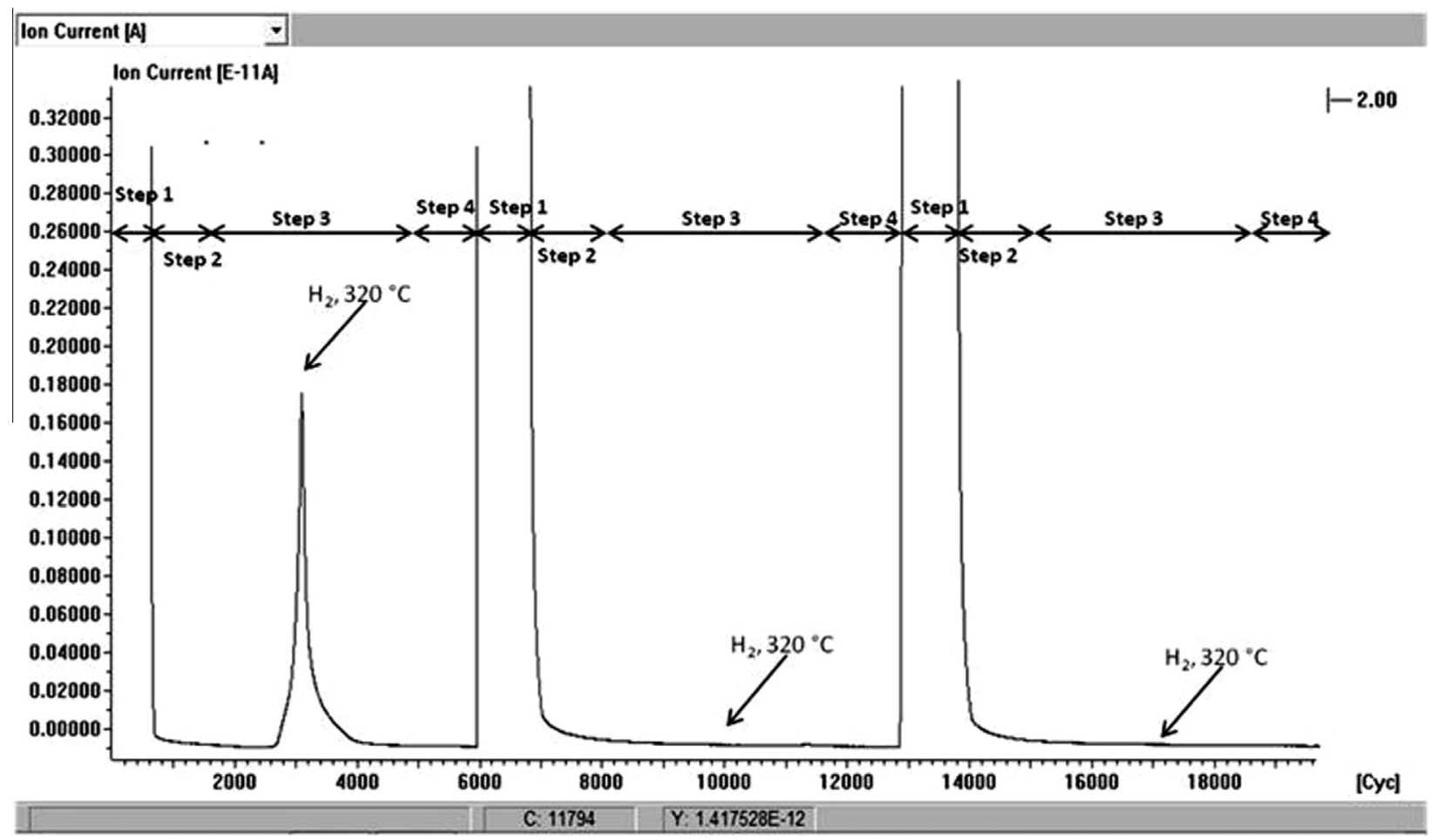

Fig. 13. TPD-MS $m / z=2$ signal obtained from reactivated Pd-corundum.

the $\alpha$-Pd to $\beta$-Pd. Some reports suggest that, once formed, $\beta$-Pd $\left(\mathrm{PdH}_{x}\right.$ with $\left.x>0.5\right)$ is not active for hydrogen activation [41]. This consideration could explain the fast deactivation of the catalytic membrane reactors with palladium loaded by sputtering. In the present case this process may be highly facilitated due to the high surface/bulk ratio. This process should be reversible according to the current scientific understanding.

Some simple experiments were carried out in order to investigate the effects of hydrogen on the sputtered palladium nanoparticles. Corundum powder with sputtered palladium described in the previous sections was used. It was tested in TPD equipment coupled to a mass detector. A cycle program was developed that attempted to achieve the reaction conditions of the hydrogen peroxide generation tests as well as the activation procedure after deactivation. The different steps as well as their purpose are presented in Table 2.

The program was repeated 3 times. Fig. 12 presents the results from the mass detector for Pd sputtered on corundum. The different steps as well as the relevant temperatures are also shown. The $y$-axis is scaled in a range where the zone of interest is clearly visualised. It can be seen from the graph that hydrogen was desorbed at $320^{\circ} \mathrm{C}$ in the first cycle. In the second cycle the peak that corresponds to hydrogen was almost undetectable. In the third cycles no hydrogen was detected. The sample was recovered and calcined at $400{ }^{\circ} \mathrm{C}$ and subsequently reduced in hydrogen flow and cooled in $\mathrm{Ar}$ atmosphere. This was the activation procedure found to be effective for the reactivation of Pd sputtered catalytic membrane reactors. Subsequently, the TPD sequence described above was repeated. The results are shown on Fig. 13. As it can be seen, the mass detector response was exactly the same as in the first case.

These experiments clearly demonstrate that hydrogen is absorbed by the palladium and probably $\beta$-Pd phase is formed. The absorbed hydrogen is strongly retained in the metal and is released at $320^{\circ} \mathrm{C}$. This temperature is similar to the one reported by other authors [44]. The results also demonstrate that some transformations of the palladium occur as can be concluded from its decreasing capacity for hydrogen storage. It is difficult to offer a plausible explanation of this observation at this stage.

Palladium nanoparticles with defined sizes (4-6 nm) have been studied at different temperatures in various environments e.g. air, inert gas, hydrogen in [44]. The metal particles have been observed by HRTEM and selected area electron diffraction (SAED). These authors observed loss of crystallinity of the metal lattice especially when Pd was in a hydrogen atmosphere. This finding was attributed to the metal support interactions occurring at high temperature.

We discard the possibility that the palladium deactivation observed with the catalytic membrane reactors is due to the interaction between the Pd and the support especially taking into account that it occurs at $60^{\circ} \mathrm{C}$.

A more extended study is underway in our laboratory in order to better understand the mechanisms involved in the palladium deactivation. In case we are able to confirm that the hydrogen plays a major role in the metal deactivation, especially for particles in the nanoscale range, additional steps will be considered for its stabilization without decreasing its activity for the hydrogen activation.

\section{Conclusions}

The catalytic membrane reactors developed here present a very attractive option for processes where hydrogen peroxide is required in-situ. The present work demonstrates their efficiency in two step reaction, direct hydrogen peroxide generation followed by phenol oxidation in water solution. The catalytic membrane reactors prepared by impregnation have shown very stable activity in the studied advanced oxidation process as well they can be used repeatedly in subsequent tests maintaining the same activities.

The use of conventional sputtering can enormously reduce the required amount of precious metal and leads to higher dispersion of the noble metal in form of nanometer-sized particles, as it was 
confirmed with the sputtered corundum powder. The reactors prepared by this technique have shown up to 1500 times higher activities than the impregnated ones per mass of incorporated Pd. Despite their advantages, we found that they lose their activities very fast. It was demonstrated that the hydrogen plays a very important role in this process. The additional experiments gave new insights for a better understanding of the Pd deactivation especially when the metal particles are in the nanometer range. These issues are currently under investigation using more precise techniques such as HRTEM coupled to XRD equipment which allows the monitoring of the morphological changes in the samples. The effects of the supports on the nano sized Pd grains are also under investigation.

\section{Acknowledgments}

O. Osegueda wants to express his gratitude for the economic support given by the pre-doctoral scholarship from Fundación Carolina, Universidad Centroamericana "José Simeón Cañas" (El Salvador) and Universitat Rovira I Virgili (Spain). F. Medina and J. Llorca are grateful to ICREA Academia program.

\section{Appendix A. Supplementary data}

Supplementary data associated with this article can be found, in the online version, at http://dx.doi.org/10.1016/j.cej.2014.09.064.

\section{References}

[1] L.J. Jian, C. Chen, F. Lan, S. Deng, W. Xiao, N. Zhang, Catalytic activity of unsaturated coordinated Cu-MOF to the hydroxylation of phenol, Solid State Sci. 13 (2011) 1127-1131.

[2] J.A. Botas, J.A. Melero, F. Martínez, M.I. Pariente, Assessment of $\mathrm{Fe}_{2} \mathrm{O}_{3} / \mathrm{SiO}_{2}$ catalysts for the continuous treatment of phenol aqueous solution in a fixed bed reactor, Catal. Today 149 (2010) 334-340.

[3] R.C. Martins, R.M. Quinta-Ferreira, Remediation of phenolic wastewaters by advanced oxidation processes (AOPs) at ambient conditions: comparative studies, Chem. Eng. Sci. 66 (2011) 3243-3250.

[4] J.A. Melero, F. Martínez, J.A. Botas, R. Molina, M.I. Pariente, Heterogeneous catalytic wet peroxide oxidation systems for the treatment of an industria pharmaceutical wastewater, Water Res. 43 (2009) 4010-4018.

[5] R. Andreozzi, C. Caprio, A. Insola, R. Marotta, Advanced oxidation processes (AOP) for water purification and recovery, Catal. Today 53 (1999) 51-59.

[6] J.M. Tatibouët, E. Guélou, J. Fournier, Catalytic oxidation of phenol by hydrogen peroxide over a pillared clay containing iron. Active species and $\mathrm{pH}$ effect, Top. Catal. 33 (2005) 225-232.

[7] A.M. De Luis, J.I. Lombraña, A. Menéndez, J. Sanz, Analysis of the toxicity of phenol solutions treated with $\mathrm{H}_{2} \mathrm{O}_{2} / \mathrm{UV}$ and $\mathrm{H}_{2} \mathrm{O}_{2} / \mathrm{Fe}$ oxidative systems, Ind. Eng. Chem. Res. 50 (2011) 1928-1937.

[8] S.P. Sung, A.T. Lemley, P-Nitrophenol degradation by a heterogeneous Fentonlike reaction on nano-magnetite: process optimization, kinetics and degradation pathways, J. Mol. Catal. A Chem. 349 (2011) 71-79.

[9] Y.Y. Zhang, C. He, V.K. Sharma, X.Z. Li, S.H. Tian, Y. Xiong, A new reactor coupling heterogeneous Fento-like catalytic oxidation with membrane separation for degradation of organic pollutants, J. Chem. Technol. Biotechnol. 86 (2011) 1488-1494.

[10] S.K. Bhargava, J. Tardio, J. Prasad, K. Föer, D.B. Akolekar, S.C. Grocott, Wet oxidation and catalytic wet oxidation, Ind. Eng. Chem. Res. 45 (2006) 1221 1258.

[11] M. Vospernik, A. Pintar, J. Levec, Application of a catalytic membrane reactor to catalytic wet air oxidation of formic acid, Chem. Eng. Process. 45 (2006) $404-$ 414.

[12] M. Alame, A. Abusaloua, M. Pera-Titus, N. Guilhaume, K. Fiaty, A. GiroirFendler, High performance catalytic wet air oxidation (CWAO) of organic acids and phenol in interfacial catalytic membrane contactors under optimized wetting conditions, Catal. Today 157 (2010) 327-333.

[13] S. Melada, F. Pinna, G. Strukul, S. Perathoner, G. Centi, Palladium modified catalytic membranes for the direct synthesis of $\mathrm{H}_{2} \mathrm{O}_{2}$ : preparation and performance in aqueous solution, J. Catal. 235 (2005) 241-248.

[14] A. Pashkova, K. Svajda, R. Dittmeyer, Direct synthesis of hydrogen peroxide in a catalytic membrane reactor, Chem. Eng. J. 139 (2008) 165-171.

[15] T. Inoue, Y. Tanaka, D.A. Pacheco Tanaka, T.M. Susuki, K. Sato, M. Nishioka, S. Hamakawa, F. Mizukami, Direct production of hydrogen peroxide from oxygen and hydrogen applying membrane permeation mechanism, Chem. Eng. Sci. 65 (2010) 436-440.

[16] A. Pashkova, R. Dittmeyer, N. Kalterborn, H. Ritcher, Experimental study of porous catalytic membranes for direct synthesis of hydrogen peroxide, Chem. Eng. J. 165 (2010) 924-933.

[17] L. Shi, A. Goldbach, G. Zeng, H. Xu, $\mathrm{H}_{2} \mathrm{O}_{2}$ synthesis over PdAu membranes, Catal. Today 156 (2010) 118-123.

[18] L. Shi, A. Goldbach, G. Zeng, H. Xu, Direct $\mathrm{H}_{2} \mathrm{O}_{2}$ synthesis over Pd membranes at elevated temperatures, J. Memb. Sci. 348 (2010) 160-166.

[19] O. Osegueda, A. Dafinov, J. Llorca, F. Medina, J. Sueiras, In situ generation of hydrogen peroxide in catalytic membrane reactor, Catal. Today 193 (2012) $128-136$.

[20] R. Dittmeyer, K. Svajda, M. Reif, A review of catalytic membrane layers for gas liquid reactions, Top. Catal. 29 (2004) 3-27.

[21] R. Burch, P.R. Ellis, An investigation of alternative catalytic approach for the direct synthesis of hydrogen peroxide from hydrogen and oxygen, Appl. Catal. B Environ. 42 (2003) 203-211.

[22] O.P. Pestunova, O.L. Ogorodnikova, V.N. Parmon, Studies of phenol wet peroxide oxidation in presence of solid catalyst, Chem. Sustain. Dev. 11 (2003) 227-232.

[23] B. Zhao, B. Shi, X. Zhang, X. Cao, Y. Zhang, Catalytic wet hydrogen peroxide oxidation of $\mathrm{H}$-acid in aqueous solution with $\mathrm{TiO}_{2}-\mathrm{CeO}_{2}$ and $\mathrm{Fe} / \mathrm{TiO}_{2}-\mathrm{CeO}_{2}$, Desalination 268 (2011) 55-59.

[24] E.G. Heckert, S. Seal, W.T. Self, Fenton-like reaction catalyzed by the rare earth inner transition metal cerium, Environ. Sci. Technol. 48 (2008) 5014-5019.

[25] A.K. Talukdar, K.G. Bhattacharyya, Hydrogenation of phenol over supported platinum and palladium catalyst, Appl. Catal. A Gen. 96 (1993) 229-239.

[26] E. Díaz, A.F. Mohedano, L. Calvo, M.A. Gillarraz, J.A. Casas, J.J. Rodríguez, Kinetics of 4-chlorophenol hydrodechlorination with alumina and activated carbon supported Pd and Rh catalysts, Chem. Eng. J. 131 (2007) 65-71.

[27] H. Liu, T. Jiang, B. Han, S. Liang, Y. Zhou, Selective phenol hydrogenation to cyclohexanone over dual supported Pd-Lewis acid catalyst, Science 326 (2009) 1250-1252.

[28] K. Mori, K. Furubayashi, S. Okada, H. Yamashita, Unexpected Pd-catalyzed hydrogenation of phenol to 2-cyclohexene-1-one: enhance activity and selectivity assisted by molecular oxygen, Chem. Commun. 48 (2012) 88868888.

[29] V.R. Choudhary, Y.V. Ingole, C. Samanta, P. Jana, Direct oxidation of hydrogen to hydrogen peroxide over $\mathrm{Pd}$ (or $\mathrm{PdO}) / \mathrm{Al}_{2} \mathrm{O}_{3}$ in aqueous reaction medium: influence of different acids and halides anions in reaction medium on formation and destruction of $\mathrm{H}_{2} \mathrm{O}_{2}$, Ind. Eng. Chem. Res. 46 (2007) 8566-8573.

[30] P.A. Weyrich, H. Treviño, W.F. Hölderich, W.M.H. Sachtler, Characterization of Ce promoted, zeolite supported Pd catalysts, Appl. Catal. A Gen. 163 (1997) 31-44.

[31] M.F. Luo, Z.Y. Hou, X.X. Yuan, X.M. Zheng, Characterization study of $\mathrm{CeO}_{2}$ supported Pd catalyst for low-temperature carbon monoxide oxidation, Catal. Lett. 50 (1998) 205-209.

[32] C.E. Gigola, M.S. Moreno, I. Costilla, M.D. Sánchez, Characterization of $\mathrm{Pd}-\mathrm{CeO}_{x}$ interaction on $\alpha-\mathrm{Al}_{2} \mathrm{O}_{3}$ support, Appl. Surf. Sci. 254 (2007) 325-329.

[33] H. Idriss, Ethanol reactions over the surfaces of noble metal/cerium oxide catalyst, Platin. Met. Rev. 48 (2004) 105-115.

[34] M.P. Kapoor, Y. Ichihashi, K. Yuichi, W.J. Shen, Y. Matsumura, Catalytic methanol decomposition over palladium deposited on mesoporous cerium oxide, Catal. Lett. 88 (2003) 83-87.

[35] A. Adrover, M. Giona, L. Capobianco, V. Violante, Effect of self-stress on hydrogen diffusion in Pd membranes in the coexistent of $\alpha$ and $\beta$ phases, J. Alloy Comp. 368 (2004) 287-297.

[36] F.A. Lewis, The hydrides of palladium and palladium alloys, Platin. Met. Rev. 4 (1960) 132-137.

[37] M. Johansson, E. Skúlason, G. Nielsen, S. Murphy, R.M. Nielsen, I. Chorkendorff, Hydrogen absorption on palladium and palladium hydride at 1 bar, Surf. Sci. 604 (2010) 718-729.

[38] D. Wang, J. Tong, H. Xu, Y. Matsumura, Preparation of palladium membranes over porous stainless steel tube modified with zirconium oxide, Catal. Today 93-95 (2004) 689-693.

[39] R.J. Rennard, R.J. Kokes, Hydrogenation of ethylene and propylene over palladium hydride, J. Phys. Chem. A 70 (1966) 2543-2549.

[40] A. Benedetti, G. Fagherazzi, F. Pinna, G. Rampazzo, M. Selva, G. Strukul, The influence of a second phase metal component ( $\mathrm{Cu}, \mathrm{Sn}, \mathrm{Fe}$ ) on $\mathrm{Pd} / \mathrm{SiO}_{2}$ activity in the hydrogenation of 2,4-dinitrotoluene, Catal. Lett. 10 (1991) 215.

[41] Á. Mastalir, Z. Király, F. Berger, Comparative study of size-quantized Pdmontmorillonite catalysts in liquid-phase semihydrogenations of alkynes, Appl. Catal. A Gen. 269 (2004) 161-168.

[42] J. Panpranot, O. Tangjitwattakorn, P. Praserthdam, J.G. Goodwind, Effects of Pd precursors on the catalytic activity and deactivation of silica-supported $\mathrm{Pd}$ catalysts in liquid phase hydrogenation, Appl. Catal. A Gen. 292 (2005) 322 327.

[43] P. Albers, J. Pietsch, S.F. Parker, Poisoning and deactivation of palladium catalysts, J. Mol. Catal. A Chem. 173 (2001) 275-286.

[44] B. Jenewein, S. Penner, H. Gabash, B. Klötzer, D. Wang, A. Knop-Gericke, R. Schlögl, K. Hayek, Hydride formation and stability on a $\mathrm{Pd}-\mathrm{SiO}_{2}$ thin film model catalyst studied by TEM and SAED, J. Catal. 241 (2006) 155-161. 